\title{
Pemanfaatan Autoclave Model 1925x Sebagai Alat Suling dengan Model Kondensor Graham dan Kondensor Allihn untuk Mendukung Praktikum Mahasiswa di Laboratorium Produksi Tanaman II Politeknik Negeri Lampung
}

\author{
Alqum ${ }^{1}$, Nono Tarsono. $G^{2}$ \\ 1Politeknik Negeri Lampung, Bandar Lampung,35144, email: alqum57@gmail.com \\ 2Politeknik Negeri Lampung, Bandar Lampung,35144, email: ntarsono1963g@gmail.com
}

Submisi: 12 Agustus 2019; Penerimaan: 18 September 2019

\begin{abstract}
ABSTRAK
Autoclave model 1925X yang berfungsi pokok sebagai alat sterilisasi dapat dimanfaatkan fungsinya sebagai alat suling minyak atsiri dengan penggunaan bahan yang relatif sedikit dengan menambahkan model kondensor Graham dan kondensor Allihn. Perancangan alat penyulingan menggunakan autoclave sebagai alat suling dengan menambahkan kondensor Graham dan Allihn diharapkan dapat menghasilkan minyak atsiri dengan kualitas yang baik dengan rendemen yang tinggi. Modifikasi autoclave selain fungsi pokoknya sebagai alat sterilisasi juga dapat dioptimalkan fungsi lainnya yaitu sebagai alat penyulingan minyak atsiri akan mampu memberikan pelayanan yang optimal pada praktikum dan penelitian di Laboratorium. Tujuan penelitian ini adalah: (1) Mengetahui kemampuan autoclave sebagai sebagai alat suling minyak atsiri. (2) Mengetahui rendemen minyak atsiri yang dihasilkan autoclave sebagai optimalisasi fungsi alat suling dengan menggunakan jenis kondensor graham dan kondensor allihn. Metode analisis yang dipakai untuk menentukan apakah hasil perancangan alat suling autoclave model 1925X dengan menggunakan dua jenis kondensor yaitu Kondensor tipe graham dan Kondensor tipe allihn memberikann hasil rendemen minyak atsiri yaitu dengan uji deskriptik.

Hasil penelitian menunjukan penggunaan autoclave dengan menggunakan kondensor tipe graham waktu keluar kondesat awal bahan sereh wangi 9,10 menit, nilam 14,61 menit, dan rimpang jahe 7,47 menit. Sedangkan rendemen bahan sereh wangi $0,44 \%$, daun nilam $3.10 \%$ dan bahan rimpang jahe 1,42\%. Sedangkan hasil penelitian dengan menggunakan kondensor Allihn waktu keluar kondesat awal bahan sereh wangi 9,10 menit, daun nilam 12,31 menit dan rimpang jahe 7,47 menit. Sedangkan rendemen bahan sereh wangi 0,24\%, daun nilam $2.03 \%$ dan bahan rimpang jahe $0,10 \%$. Rendemen minyak atsiri berbahan sereh wangi standar $S N I=1,2 \%$, nilam standar $S N I=5,5 \%$ dan bahan rimpang jahe Standar $S N I=1,50 \%$. Penelitian ini menunjukan bahwa dengan kondensor Graham menghasilkan rendemen yang lebih tinggi antara 34,5\% sampai dengan 92,9\% bila dibandingkan dengan kondensor Allihn. Mampu menghasilkan minyak atsiri 63,7 \% terhadap standar SNI.
\end{abstract}

Kata kunci: autoclave model 1925X; kondensor graham; kondensor allihn.

\section{PENDAHULUAN}

Autoclave model $1925 X$
mempunyai fungsi pokok untuk
mensterlisasi alat-alat laboratorium dan
media. Autoclave model $1925 X$ adalah
alat pemanas tertutup yang digunakan untuk mensterilisasi suatu benda menggunakan tekanan uap bersuhu 250 ${ }^{\circ} \mathrm{F}$ dan bertekanan 17 psi setara dengan $121^{\circ} \mathrm{C}, 15 \mathrm{lbs}$ selama kurang lebih 15 menit. Peningkatan tekanan pada autoclave tidak dimaksudkan untuk 
membunuh mikroorganisme, melainkan meningkatkan suhu. Dalam autoclave suhu yang tinggi berfungsi sebagai seterilisasi media dan alat yang membunuh mikro organisme. Autoclave terutama ditujukan untuk membunuh endospora, yaitu sel resisten yang diproduksi oleh bakteri, sel ini tahan terhadap pemanasan, kekeringan, dan antibiotik. Pada spesies yang sama, endospora dapat bertahan pada kondisi lingkungan yang dapat membunuh sel vegetatif bakteri tersebut. Endospora dapat dibunuh pada suhu $100^{\circ} \mathrm{C}$, yang merupakan titik didih air pada tekanan atmosfer normal. Pada suhu $121^{\circ} \mathrm{C}$, endospora dapat dibunuh dalam waktu 4-5 menit, dimana sel vegetatif bakteri dapat dibunuh hanya dalam waktu 6-30 detik pada suhu $65^{\circ} \mathrm{C}$.

Perhitungan waktu sterilisasi autoclave dimulai ketika suhu di dalam autoclave mencapai $121^{\circ} \mathrm{C}$. Jika objek yang disterilisasi cukup tebal atau banyak, transfer panas pada bagian dalam autoclave akan melambat, sehingga terjadi perpanjangan waktu pemanasan total untuk memastikan bahwa semua objek bersuhu $121^{\circ} \mathrm{C}$ untuk waktu 10 sampai dengan 15 menit. Perpanjangan waktu juga dibutuhkan ketika cairan dalam volume besar akan diautoklaf karena volume yang besar membutuhkan waktu yang lebih lama untuk mencapai suhu sterilisasi. Performa autoclave diuji dengan indikator biologi, contohnya Bacillus stearothermophilus.

Autoclave model 1925X yang berfungsi pokok sebagai seterlisasi dapat dioptimalisasi fungsi nya sebagai alat suling minyak atsiri dengan penggunaan bahan yang relatif sedikit dengan menambahkan kondensor Graham dan atau Allihn.

Terdapat tiga jenis autoclave yaitu gravity displacement, prevacuum atau high vacuum, dan steam-flush pressure- pulse. Perbedaan ketiga jenis autoclave ini terletak pada bagaimana udara dihilangkan dari dalam autoclave selama proses sterilisasi.

$\begin{array}{crr}\text { Alat } & \text { penyulingan } & \text { dengan } \\ \text { menggunakan autoclave } & \text { yang }\end{array}$ dimodifikasi menjadi alat ketel suling dapat memberikan pemahaman bagi mahasiswa tentang alat penyulingan. Rancang bangun alat penyulingan menggunakan autoclave sebagai alat suling diharapkan dapat menghasilkan minyak atsiri dengan kualitas yang baik dengan rendemen minyak atsiri yang tinggi.

Usaha memanfaatan autoclave selain sebagai alat sterilisasi alat dan media sebagai fungsi pokoknya dengan mengoptimalkan fungsi lain sebagai alat penyulingan minyak atsiri diharapkan mampu memberikan pelayanan yang optimal pada praktikum dan penelitian di Laboratorium Produksi Tanaman II

Perumusan Masalah, Berdasarkan latar belakang dan identifikasi masalah, maka dapat dirumuskan masalah: 1. Bagaimanakah usaha memanfaatan autoclave model 1925X dapat berfungsi sebagai alat suling menggunakan kondensor Graham dan Allihn? .2. Berapakah rendemen minyak atsiri yang dihasilkan autoclave model 1925X sebagai optimalisasi fungsi alat suling dengan menggunakan dua kondensor Graham dan Allihn?

Tujuan yang ingin dicapai pada penelitian ini adalah: Untuk mengetahui kemampuan autoclave model 1925X selain alat sterilisasi dapat dioptimalisasi fungsinya sebagai alat suling minyak atsiri, untuk mengetahui rendemen minyak atsiri yang dihasilkan autoclave model 1925X sebagai optimalisasi fungsi alat suling dengan menggunakan jenis

Kegunaan Penelitian ini adalah membuktikan secara ilmiah pemanfaatan 
autoclave dengan menambahkan kondesor dapat berfungsi sebagai alat suling minyak atsiri, mengetahui rendemen minyak atsiri yang dihasilkan dalam penyulingan menggunakan autoclave dengan dua jenis kondensor yang berbeda, Sebagai referensi bagi penelitian lebih lanjut tentang penyulingan minyak atsiri dan memberi kontribusi kepada PLP untuk meningkatkan kinerja.

\section{METODE PENELITIAN}

Penelitian dilaksanakan di Laboratorium Produksi Tanaman II Politeknik Negeri Lampung Peralatan yang dipakai dalam penelitian terdiri dari: autoclave, kondensor Graham, kondensor Allihn, kompor gas, beaker glass $500 \mathrm{ml}$ dan beaker glass $1000 \mathrm{ml}$, statif, separating funnel, selang plastik tahan panas, besi pipa berbentuk $L$ diameter $0,9 \mathrm{~cm}$, sarangan dan bahan yang digunakan dalam penelitian ini adalah sereh wangi, nilam, rimpang jahe

Metoda Analisis yang digunakan untuk menentukan apakah hasil perancangan autoclave sebagai alat suling memberikan pengaruh terhadap hasil penyulingan minyak atsiri, waktu keluarnya kondesat pertama dan rendemen yang dihasilkan menggunakan komputer dengan uji deskriptik. Metoda analisis yang dipakai untuk menentukan apakah hasil perancangan alat suling autoclav dengan menggunakan dua jenis kondensor yaitu kondesor Graham dan kondensor Allihn memberikan hasil rendemen minyak atsiri yaitu dengan uji beda parametik dengan metode $t$ Test dengan menggunakan komputer program SPSS statistik 17,0 pada taraf signifikan 0,05.

\section{Pelaksanaan}

Penelitian

melakukan perancangan alat autoclave dengan dua jenis kondensor, rancang bangun alat autoclave perlu dilakukan agar dapat difungsikan sebagai ketel suling dalam penyulingan minyak atsiri. Prosedur rancang bangun sebagai berikut : membuka karet penutup pada lubang bulat kecil yang ada pada penutup autoclave membuat pipa besi berbentuk $L$ dengan tinggi $8 \mathrm{~cm}$, panjang $22 \mathrm{~cm}$ dan diameter $0,9 \mathrm{~cm}$ yang berfungsi untuk keluarnya uap dari ketel suling, membuat penghubung uap yang keluar dari ketel suling menuju ke kondensor dengan menggunakan selang plastik yang tahan panas berukuran panjang $20 \mathrm{~cm}$ dan diameter $10 \mathrm{~cm}$, membuat sarangan berbahan dasar alumunium untuk memisahkan bahan dan air pada ketel suling dengan diameter $30 \mathrm{~cm}$ dan tinggi $14 \mathrm{~cm}$, yang digunakan dalam penyulingan dengan teknik uap dan air.

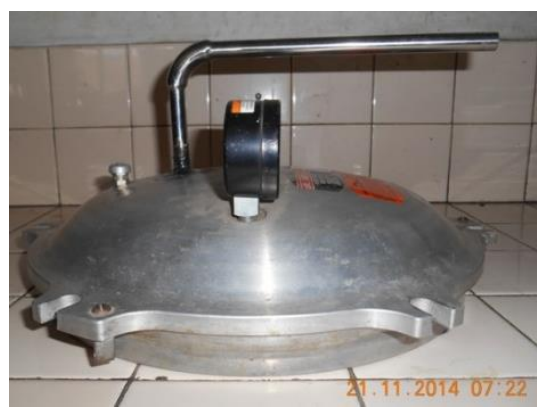

a

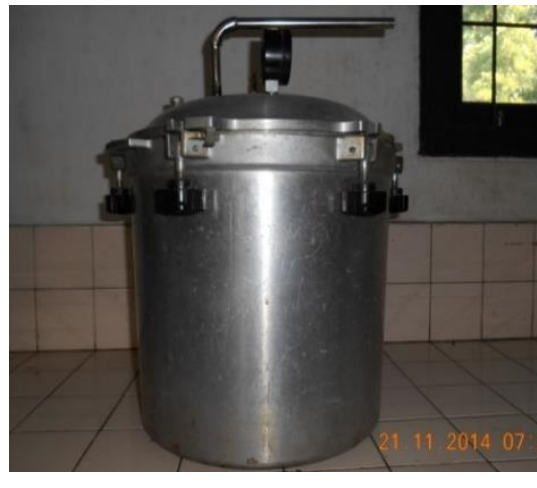

b

Gambar 1. a. Pipa besi berbentuk $L$ dipasang pada tutup autoclave sebagai tempat keluarnya uap air yang mengandung minyak atsiri, b. Autoclave sebagai ketel suling. 


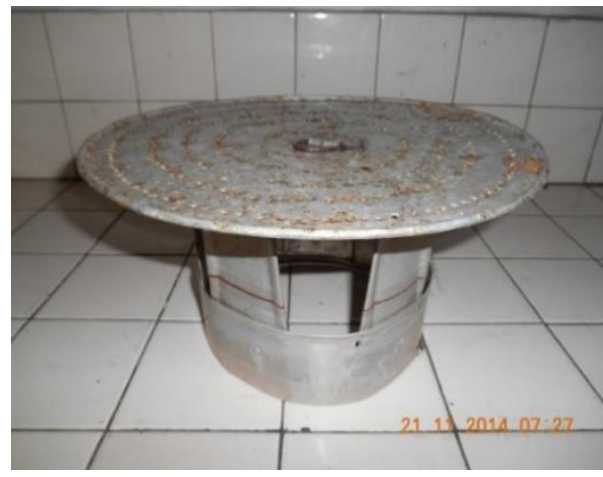

a

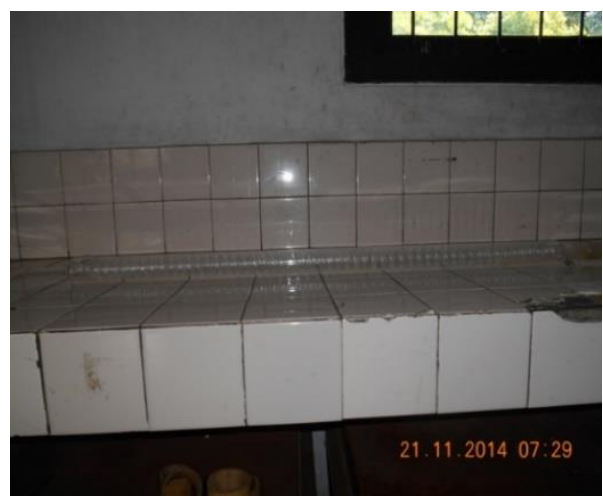

b

Gambar 2. a. Sarangan untuk memisahkan bahan dan air dalam penyulingan teknik air dan uap, b. Kondensor.

Merangkai alat autoclave hasil modifikasi menjadi alat penyulingan ini. Autoclave hasil modifikasi perlu dirangkai dengan berbagai peralatan lain agar dapat berfungsi sebagai Alat Penyulingan Mini dengan prosedur seperti berikut :

Memasang besi pipa berbentuk $L$ pada tutup autoclave yang telah dibuka penutup karetnya yang berfungsi sebagai tempat keluarnya uap, meletakkan autoclave sebagai ketel suling di atas kompor gas sebagai alat pemanas pada proses penyulingan, menghubungkan pipa pada autoclave dengan kondensor pada statif menggunakan selang plastik tahan panas. Memasukkan dan mengeluarkan air dari kran ke kondensor menggunakan selang plastik tahan air sebagai proses pendinginan. membuat tempat penampung kondensat yang keluar dari kondensor menggunakan beaker glass, memasang sarangan yang terbuat dari alumunium pada autoclave apabila akan dilakukan penyulingan teknik air dan uap.

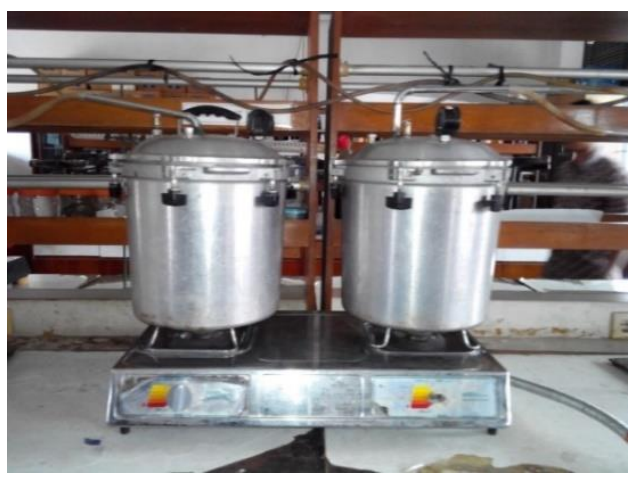

a

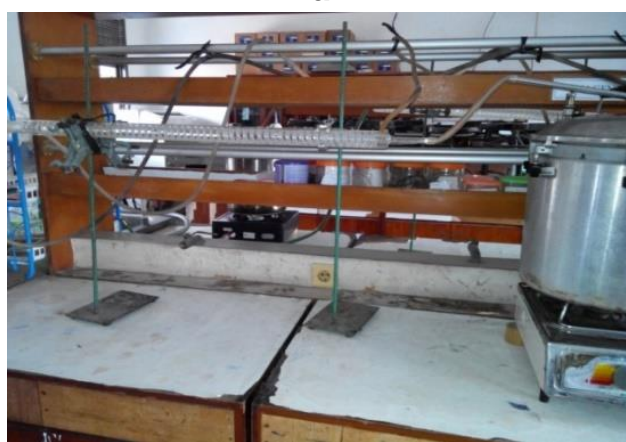

b.

Gambar 3. a dan b Rangkaian alat pemanas, ketel suling dan kondensor sebagai alat penyulingan .

Proses penyulingan minyak atsiri dilakukan dengan teknik air dan teknik penyulingan air dan uap. tergantung bahan baku yang akan disuling, dan prosedurnya sebagai berikut: membersihkan dan mencuci alat-alat yang akan dipakai. merangkai alat penyulingan sesuai metode penyulingan yang dikehendaki yaitu penyulingan teknik air dan penyulingan teknik air dan uap,. menyiapkan bahan baku yang akan disuling dengan cara penjemuran, pengecilan ukuran bahan, penggilingan dan lain-lain tergantung bahan baku yang akan disuling., mengisi ketel suling dengan air bersih dan mencatat 
volumenya, memasukkan bahan yang akan disuling, lalu tutup ketel suling dengan rapat.jidupkan kompor gas sebagai pemanas ketel suling, catat waktu yang diperlukan saat mulai mengeluarkan kondensat. pisahkan segera minyak dari kondensat dengan funnel separating, hitung bobot minyak atsiri dan rendemennya.

Desain Penelitian. Bahan-bahan yang digunakan penelitian rancang bangun autoclave Sebagai Alat Penyulingan Mini pada Praktikum Penyulingan Minyak Atsiri, terdiri dari: rimpang jahe, bunga kenanga, biji pala, bunga cengkeh dan nilam. Bahan-bahan tersebut ditimbang dahulu sebagai berat awal, pengamatan meliputi waktu keluarnya kondensat awal, berat minyak atsiri dan rendemen yang dihasilkan.

Tabel: 1 Desain penelitian

\begin{tabular}{lcccc}
\hline Nama Bahan & $\begin{array}{c}\text { Berat } \\
\text { Bahan } \\
(\mathrm{gr})\end{array}$ & $\begin{array}{c}\text { Waktu keluar kondensat } \\
\text { awal }\end{array}$ & $\begin{array}{c}\text { Berat } \\
\text { Minyak } \\
(\mathrm{gr})\end{array}$ & $\begin{array}{c}\text { Rendemen } \\
(\%)\end{array}$ \\
\hline Sereh wangi & & & \\
Nilam & & & \\
Rimpang jahe & & & \\
Rata-rata & & & \\
\hline
\end{tabular}

\section{HASIL DAN PEMBAHASAN}

Bahan-bahan yang digunakan
penelitian rancang bangun autoclave
sebagai alat penyulingan pada Praktikum Penyulingan Minyak Atsiri, terdiri dari: Sereh wangi, daun nilam dan rimpang jahe. Bahan-bahan tersebut ditimbang dahulu sebagai berat awal, pengamatan meliputi waktu keluarnya kondensat awal, berat minyak atsiri dan rendemen yang dihasilkan. Hasil penelitian tersebut dapat dilihat pada Tabel 2. Berdasarkan hasil penelitian pada Tabel 2, Waktu keluar kondesat awal bahan sereh wangi 9,10 menit, daun nilam 14,61 menit dan rimpang jahe 7,47 menit. Sedangkan rendemen bahan sereh wangi $0,44 \%$, daun nilam $3.10 \%$ dan bahan rimpang jahe $1,42 \%$.

Berdasarkan Tabel: 3 terdapat perbedaan hasil rendemen minyak atsiri berdasarkan SNI dengan rendemen minyak yang diperoleh dari modifikasi autoclave dengan kondensor Graham. Berdasarkan hasil penelitian pada Tabel 4: Waktu keluar kondesat awal bahan sereh wangi 9,10 menit, daun nilam 12,31 menit dan rimpang jahe 7,47 menit. Sedangkan rendemen bahan sereh wangi $0,24 \%$, daun nilam $2.03 \%$ dan bahan rimpang jahe $0,10 \%$.

Tabel 2. Waktu keluar kondesat awal dan rendemen minyak yang diperoleh dari modifikasi autoclave dengan Kondensor Graham

\begin{tabular}{ccc}
\hline \multirow{2}{*}{ Nama Bahan } & \multicolumn{2}{c}{ Rerata tiga kali ulangan } \\
& Waktu keluar kondesat awal (menit) & Rendemen (\%) \\
\hline Sereh wangi & 9,10 & 0,44 \\
Daun nilam & 14,61 & 3,10 \\
Rimpang jahe & 7,47 & 1,42 \\
\hline
\end{tabular}


Tabel 3. Perbandingan rendemen minyak atsiri berdasar SNI dan rendemen minyak yang diperoleh dari modifikasi autoclave model $1925 \mathrm{X}$

\begin{tabular}{ccc} 
Nama & Rendemen berdasarkan & $\begin{array}{c}\text { Rerata tiga kali ulangan (\%) } \\
\text { Rendemen autoclave model 1925X dengan kondensor } \\
\text { Braham }\end{array}$ \\
\hline Sereh wangi & $0,97-1,2$ & 0,44 \\
Daun nilam & 5,5 & 3,10 \\
Rimpang & 1,50 & 1,42 \\
jahe & & \\
\hline
\end{tabular}

Tabel 4. Waktu keluar kondesat awal dan rendemen minyak yang diperoleh dari modifikasi autoclave model $1925 X$ dengan kondensor Allihn

\begin{tabular}{ccc}
\hline Nama Bahan & Rerata tiga kali ulangan & \\
& Waktu keluar kondesat awal (menit) & Rendemen \\
\hline Sereh wangi & 9,10 & 0,24 \\
Daun nilam & 12,31 & 2,03 \\
Rimpang jahe & 7,47 & 0,10 \\
\hline
\end{tabular}

Tabel 5. Perbandingan rendemen minyak atsiri berdasar SNI dan rendemen minyak yang diperoleh dari modifikasi autoclave model 1925X kondensor Allihn

\begin{tabular}{ccc}
$\begin{array}{c}\text { Nama } \\
\text { Bahan }\end{array}$ & $\begin{array}{c}\text { Rendemen berdasarkan } \\
\text { SNI }\end{array}$ & $\begin{array}{c}\text { Rerata tiga kali ulangan (\%) } \\
\text { Rendemen autoclave model 1925X dengan } \\
\text { kondensor Allihn }\end{array}$ \\
\hline $\begin{array}{c}\text { Sereh } \\
\text { wangi }\end{array}$ & $0,97-1,2$ & 0,24 \\
$\begin{array}{c}\text { Daun nilam } \\
\text { Rimpang } \\
\text { jahe }\end{array}$ & 5,5 & 2,03 \\
\hline
\end{tabular}

Berdasarkan Tabel: 5 terdapat perbedaan hasil rendemen minyak atsiri berdasarkan SNI dengan hasil rendemen minyak yang diperoleh dari modifikasi autoclave model 1925X dengan kondensor Allihn. Berdasarkan Tabel: 6 terdapat perbedaan hasil rendemen minyak atsiri berdasarkan SNI dengan hasil rendemen minyak yang diperoleh dari modifikasi Autoclave Model 1925X kondensor graham dan kondensor allihn.

Tabel 6. Perbandingan rendemen minyak atsiri berdasar SNI dan rendemen minyak yang diperoleh dari modifikasi autoclave model 1925X, kondensor Graham dan Allihn

\begin{tabular}{cccc}
\hline Nama Bahan & Rerata tiga kali ulangan & $\begin{array}{c}(\%) \\
\text { Rendemen } \\
\text { autoclave } \\
\text { dengan } \\
\text { kondensor } \\
\text { Allihn }\end{array}$ \\
\hline Sereh wangi & $0,97-1,2$ & $\begin{array}{c}\text { Rendemen autoclave dengan } \\
\text { kondensor Graham }\end{array}$ & 0,24 \\
Daun nilam & 5,5 & 0,44 & 2,03 \\
Rimpang jahe & 1,50 & 3,10 & 0,10 \\
\hline
\end{tabular}

\section{KESIMPULAN}

1925X Penggunaan autoclave model

kondensor Graham waktu keluar kondesat awal bahan sereh wangi 9,10 menit, daun nilam 14,61 menit dan rimpang jahe 7,47 menit. Sedangkan 
rendemen bahan sereh wangi 0,44\%, daun nilam $3.10 \%$ dan bahan rimpang jahe $1,42 \%$. Hasil penelitian penggunaan autoclave model 1925X dengan menggunakan kondensor Allihn waktu keluar kondesat awal bahan sereh wangi 9,10 menit, daun nilam 12,31 menit dan rimpang jahe 7,47 menit. Sedangkan rendemen bahan sereh wangi $0,24 \%$, daun nilam $2.03 \%$ dan bahan rimpang jahe $0,10 \%$.

Perbandingan rendemen SNI, rendemen modifikasi autoclave model 1925X dengan

kondensor Graham dan modifikasi autoclave model 1925X dengan kondensor Allihn bahan sereh wangi Standar $\mathrm{SNI}=1,2 \%$ sedangkan modifikasi autoclave dengan kondensor Graham $0,44 \%$ dan modifikasi autoclave dengan Allihn $=0,24 \%$, daun nilam Standar SNI $=5,5 \%$ sedangkan modifikasi autoclave dengan kondensor Graham $=3,10 \%$ dan modifikasi autoclave dengan kondensor Allihn= $2,03 \%$. Bahan rimpang jahe Standar $\mathrm{SNI}=1,50 \%$ sedangkan modifikasi autoclave dengan Kondensor Graham $1,42 \%$ dan modifikasi autoclave dengan Allihn $=0,10 \%$.

\section{DAFTAR PUSTAKA}

Abdulrajak, R. 1985. Penyulingan Minyak Cengkeh dan Minyakminyak Atsiri Lainnya Ganeca Exact. Bandung.

Ersan dan Rachmad Edison, 2010 , Buku Panduan Praktikum (BPP) Pengolahan Hasil Tanaman Perkebunan II (PTK 1501). Politeknik Negeri Lampung.

Indrawati Ganjar, Wellyzar Sjamsuridzal dan Ariyanti Oetari. 2006. Mikologi Dasar Dan Terapan. Obor Indonesia. Jakarta.

Ketaren, S. 1987. Minyak Atsiri jilid I s.d VI (terjemahan). UI Press. Jakarta. 